\title{
THE COMPLETE AMINO ACID SEQUENCE OF THE FOLATE-BINDING PROTEIN FROM COW'S MILK
}

\author{
by \\ IB SVENDSEN \\ Department of Chemistry, Carlsberg Laboratory, \\ Gamle Carlsbergvej 10, DK-2500 Copenhagen Valby \\ and \\ STEEN INGEMANN HANSEN, JAN HOLM and JØRGEN LYNGBYE \\ Department of Clinical Chemistry, Research Division, \\ Central Hospital, Heisevej 2, DK-3400 Hillerød
}

Keywords: Molecular weight, glucoprotein, streptococcal protease

\begin{abstract}
The complete amino acid sequence of the folate binding protein from cow's milk has been determined by automated sequencing of fragments obtained by cleavage with cyanogen bromide, trypsin, $\mathrm{S}$. aureus $\mathrm{V} 8$ protease and clostripain. The molecule consists of a single polypeptide chain of 222 amino acid residues and eight disulphide bridges. The molecular weight of the protein part is 25,700 . The folate binder contains carbohydrate which gives it a final molecular weight of about 30,000 . No sequence homology with other proteins has been observed.
\end{abstract}

\section{INTRODUCTION}

Proteins which specifically bind folate have been isolated from various body fluids and tissues of mammals $(1,7,12,14,15,16,18,19$, 20) and also from bacteria (9). In order to understand the function of these proteins it is important to know their structures. In a previous communication we have shown the partial amino acid sequence of the folate binding protein from cow's milk based on the cyanogen bromide fragments (16). Homology between this protein and the high and low molecular weight folate binding protein from human milk has been demonstrated (17). The present communication shows the complete amino acid sequence of the folate binding protein from cow's milk based on sequence determination of fragments generated by digestion with trypsin, Streptomyces aureus V8 protease, and clostripain.

Abbreviations: $\mathrm{CNBr}=$ Cyanogen bromide; $\mathrm{CPD}-\mathrm{Y}=$ Carboxypeptidase $\mathrm{Y} ; \mathrm{DPC}=$ Diphenylcarbamyl; DTT = Dithiothreitol; FBP = Folate binding protein; HEPES $=$ N-2-Hydroxyethylpiperazine-N'-2-ethane-sulfonic acid; HPLC = High performance liquid chromatography; 2-PE = 2-pyridylethylated; PTH = Phenylthiohydantoin; TFA $=$ Trifluoroacetic acid. 


\section{MATERIALS AND METHODS}

\section{1. Materials}

Folate binding protein FBP was prepared from cow's milk as described in ref. (16). DPCtrypsin and clostripain was from Sigma, St. Louis, U.S. A. S. aureus V8 protease from Miles Laboratories, U. S. A. Carboxypeptidase $\mathrm{Y}$ was prepared at the Carlsberg Laboratory. Biogel P6, P10, P30 and P60 were purchased from Biorad Laboratories, Richmond, U. S. A. All reagents for the sequencer were from Rathburn, Walkerburn, U. K. except ethyl acetate which was obtained from Merck, Darmstadt, F. R. G. and Polybrene which was from Pierce Rochford, U. S. A. All other reagents used were analytical grade products.

\section{2. Methods}

\section{2. 1. Cyanogenbromide fragments}

The preparation and purification of cyanogen bromide fragments from reduced and vinylethylated FBP have already been described (16). The four resulting fragments are numbered in the order in which they appear in the sequence (CNBr-I to CNBr-IV).

\section{2. 2. Analytical methods}

Amino acid analysis, automated amino acid sequence determination and carbohydrate determination were conducted as described in ref. (10).

\section{2. 3. Digestion with carboxypeptidase $Y$}

To 40 moles of CNBr-IV in one $\mathrm{ml} 0.2$ $\mathrm{M}$-ammoniumacetate $\mathrm{pH}$ 5. 0 was added CPD-Y in a molar ratio of 1:200. At suitable time-intervals aliquots were removed, the reaction stopped by addition of $1 \mathrm{M}-\mathrm{HCl}$ and the sample then applied to the amino acid analyzer.

\section{2. 4. Digestion with DPC-Trypsin}

FBP, ca $12 \mathrm{mg}$, was dispersed in $1 \mathrm{ml}$ of 0.5 M-ammonium bicarbonate and acetylated by addition of $3 \times 25 \mu$ l acetic anhydride at intervals of 10 minutes. After the last addition the reaction mixture was left for two hours at room temperature in order to hydrolyze excess of reagent. Then, $50 \mu \mathrm{l}$ of DPC-trypsin $\left(1 \mathrm{mg} \times \mathrm{ml}^{-1}\right)$ was added and the reaction mixture left for two hours with occasional adjustment of the $\mathrm{pH}$ to between 8 and 9 . Following centrifugation the supernatant was applied to a column of Biogel P30 $(0.9 \times 100 \mathrm{~cm})$ equlibrated with $30 \%$ acetic acid and eluted with the same solvent. The eluate was monitored at $280 \mathrm{~nm}$ and the relevant peaks pooled and lyophilized. The individual peaks were then reduced with mercaptoethanol and treated with 2-vinylpyridine (8) and finally fractionated under the same conditions as above.

In a different experiment the tryptic cleavage was conducted at $\mathrm{pH} 8.0$ in a $0.1 \mathrm{M}$-phosphate buffer and treated as above.

\section{2. 5. Digestion with clostripain}

CNBr-III $(8 \mathrm{mg}$ ) of reduced, vinylethylated FBP was digested with clostripain at pH 5.5 in $0.05 \mathrm{M}$-HEPES buffer $\left(0.05 \mathrm{M}\right.$ in $\mathrm{CaCl}_{2}, 2.5 \times 10^{-3}$ $M$ in DTT and $4 \mathrm{M}$ in urea) overnight at $37^{\circ} \mathrm{C}$. After centrifugation the supernatant was gel filtered on a Biogel P6 column $(1.6 \times 85 \mathrm{~cm})$ in $30 \%$ acetic acid and the elution profile monitored at $280 \mathrm{~nm}$.

\section{2. 6. Digestion with $S$. aureus V8 protease}

FBP $(46 \mathrm{mg}$ ) was dissolved in $10 \mathrm{ml}$ acetate buffer $\mathrm{pH} 4.0$ and $0.5 \mathrm{mg} \mathrm{S}$. aureus V8 protease added. The reaction mixture was left overnight at room temperature and then lyophilized. Separation of peptides was initially made by gel filtration on Biogel P30 (2.5×90 cm ) in $30 \%$ acetic acid and appropriate peaks pooled and lyophilized.

Further purification was obtained by reduction and vinylethylation as described in 2. 2.4 followed by gel filtration in the system just described.

\section{RESULTS}

Treatment of unreduced FBP with DPC-trypsin was made in the hope that the resulting peptides would separate upon gel filtration in such a way that some information would be obtained about the distribution of disulphide 
bridges. This was unfortunately not the case since the elution pattern from gel filtration on Biogel P30 showed one major peak of high molecular weight and low molecular weight peptides of no interest for the completion of the sequence or the study of disulphide bridges. Consequently, the main peak was reduced and vinylethylated. Gel filtration on Biogel P30 resulted in five peaks of which the last one was attributed to reagents (see Figure 1). Peak T-2 was rechromatographed twice on Biogel P60 resulting in a peptide the sequence of which began: $\mathrm{Val}_{109}-\mathrm{Leu}_{110^{-}}-\mathrm{Gly}_{111}-$ and which was followed 31 steps through $\mathrm{Gly}_{139}$. The numbering of the amino acids is that of the complete sequence to be discussed later (see Figure 5).

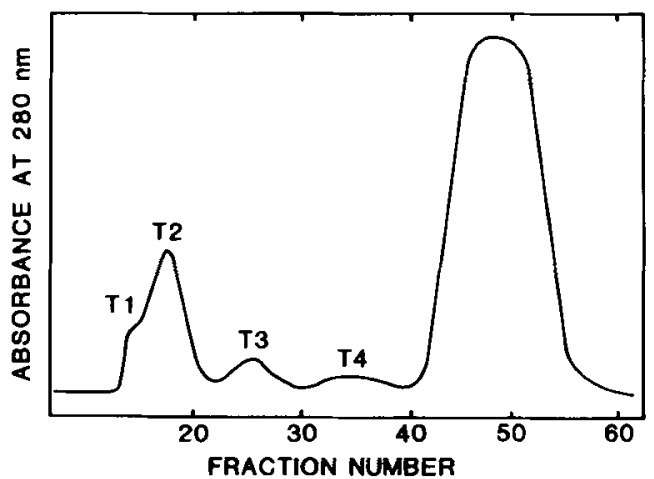

Figure 1. Gelfiltration of tryptic peptides of FBP after reduction and vinylethylation on Biogel P30 $(0.9 \times 100$ $\mathrm{cm}$ ) in $30 \%$ acetic acid. Flow-rate: $4.5 \mathrm{ml} \times \mathrm{hr}^{-1}$. Fractions: $1 \mathrm{ml}$.

Table I.

Amino acid composition of folate binding protein from cow's milk and its cyanogen bromide fragments.

\begin{tabular}{|c|c|c|c|c|c|c|c|c|c|c|}
\hline \multirow{3}{*}{$\begin{array}{l}\text { Amino } \\
\text { acid } \\
\text { Asn }\end{array}$} & \multirow{3}{*}{$12^{1)}$} & \multicolumn{2}{|l|}{ FBP } & \multirow{2}{*}{$\frac{\mathrm{CNBr}-\mathrm{I}}{1^{\prime \prime}}$} & \multicolumn{2}{|c|}{ CNBr-II } & \multicolumn{2}{|c|}{ CNBr-III } & \multicolumn{2}{|c|}{ CNBR-IV } \\
\hline & & 2) & 3) & & $2^{11}$ & & $6^{11}$ & & $3^{11}$ & \\
\hline & & $22.6(23)$ & 25 & & & $7.0(7)$ & & $10.0(10)$ & & $3.9(4)$ \\
\hline Asp & 10 & & & 1 & 4 & & 4 & & 1 & \\
\hline Thr & 10 & $10.2(10)$ & 13 & 2 & 1 & $1.2(1)$ & 5 & 4.7 (5) & 2 & $2.1(2)$ \\
\hline Ser & 17 & $17.1(17)$ & 16 & & 5 & $5.0(5)$ & 10 & $8.7 \quad(9)$ & 2 & $2.1(2)$ \\
\hline Gln & 9 & & & 1 & 1 & & 5 & & 2 & \\
\hline & & $23.6(24)$ & 24 & & & $5.4(5)$ & & $12.0(12)$ & & $5.4(5)$ \\
\hline Glu & 14 & & & & 4 & & 7 & & 3 & \\
\hline Pro & 16 & $16.0(16)$ & 16 & 2 & 3 & $3.4(3)$ & 7 & 7.1 (7) & 4 & $4.1(4)$ \\
\hline Gly & 11 & $11.4(11)$ & 13 & & 2 & $2.1(2)$ & 6 & $6.0(6)$ & 3 & $3.0(3)$ \\
\hline Ala & 14 & $13.3(13)$ & 15 & 3 & 4 & $4.1(4)$ & 5 & $4.9 \quad(5)$ & 2 & $2.1(2)$ \\
\hline Cys & 16 & $11.0(11)$ & 15 & 1 & 4 & $3.8(4)$ & 11 & $11.8(12)$ & & \\
\hline Val & 8 & $7.9 \quad(8)$ & 10 & 1 & 1 & $1.1(1)$ & 5 & $4.9 \quad(5)$ & 1 & $1.0(1)$ \\
\hline Met & 3 & $2.9 \quad$ (3) & 3 & 1 & 1 & n.d. & 1 & n.d." & & \\
\hline Ile & 7 & $6.5 \quad(7)$ & 8 & & 2 & $2.0(2)$ & 4 & 3.1 & 1 & $0.9(1)$ \\
\hline Leu & 9 & $9.6(10)$ & 12 & 2 & 2 & $2.4(2)$ & 5 & $4.5 \quad(5)$ & & \\
\hline Tyr & 9 & $8.9 \quad(9)$ & 9 & & 2 & $2.0(2)$ & 6 & $5.7 \quad(6)$ & 1 & $1.0(\mathrm{I})$ \\
\hline Phe & 8 & $7.6 \quad(8)$ & 8 & & 1 & $1.6(2)$ & 4 & $4.7 \quad(5)$ & 3 & $2.7(3)$ \\
\hline His & 8 & $8.0 \quad(8)$ & 9 & & 4 & $4.5(5)$ & 4 & $3.5 \quad(5)$ & & \\
\hline Lys & 12 & $12.5(13)$ & 13 & & 5 & $5.5(6)$ & 7 & $8.0 \quad(8)$ & & \\
\hline Arg & 15 & $14.4(14)$ & 15 & 3 & 2 & $2.3(2)$ & 9 & $7.3 \quad(7)$ & 1 & $1.0(1)$ \\
\hline Trp & 11 & 8.5 (9) & 4 & & 2 & n.d. & 8 & n.d. & 1 & n.d. \\
\hline Glucosa & amine & $5.9 \quad(6)$ & 4 & & & +++ & & +++ & & \\
\hline Total & $219+3^{5)}$ & 214 & 232 & 18 & $52+$ & & $119+$ & & 30 & \\
\hline
\end{tabular}

1) From the sequence. 2) From amino acid analysis. 3) From ref. (14). Recalculated to fit M.W. 25.700.

4) Homoserine and homoserine lactone present. +++ indicates positive carbohydrate reaction (6).

5) The numbers $+3,2$ and 1 in the total sum of amino acids refer to the vacant positions in the sequence. 


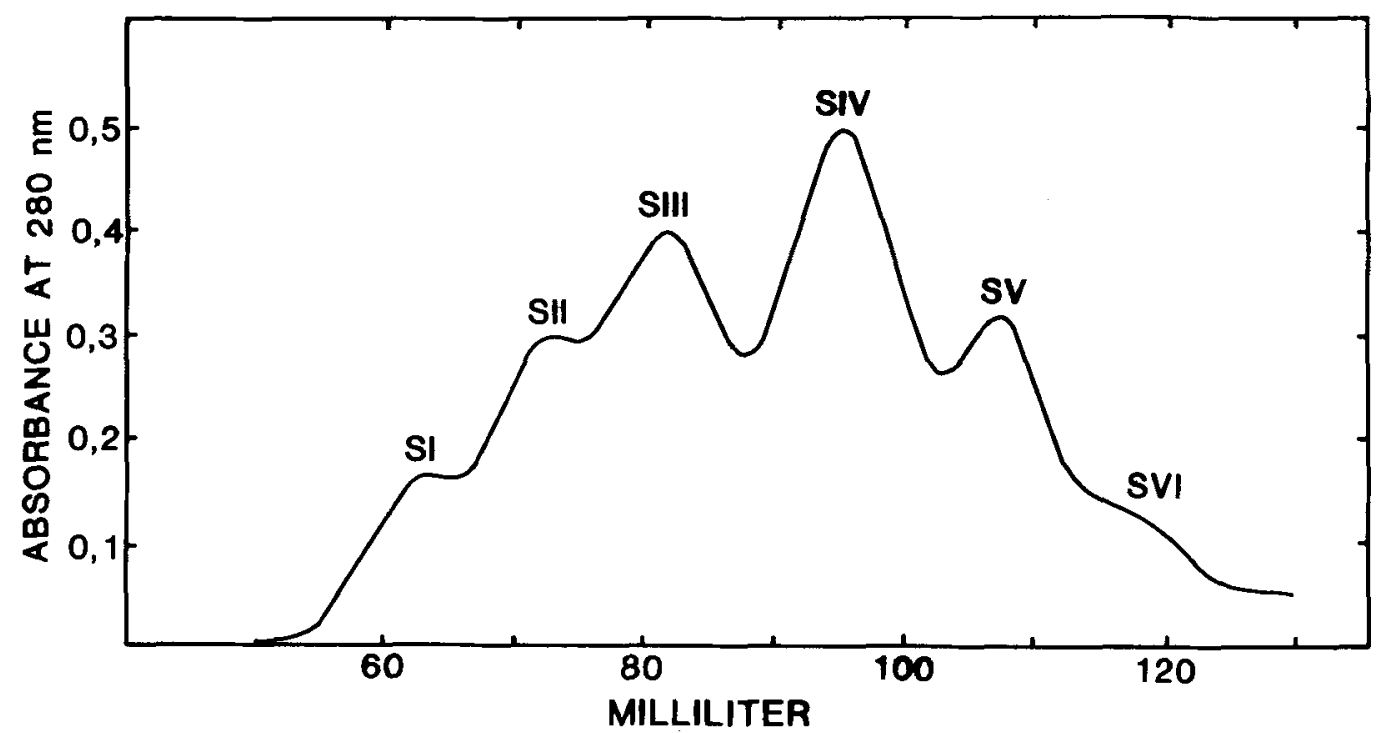

Figure 2. Gelfiltration of $\mathrm{CNBr}$-III digested with $\mathrm{S}$. aureus V8 protease on Biogel $\mathrm{P} 30(0.9 \times 165 \mathrm{~cm})$ in 0.1 M-pyridine-acetate buffer, $\mathrm{pH}$ 4. Fractions: $1 \mathrm{ml}$.

Peak T-4 (Figure 1) contained Met and sequence determination showed two peptides one of which began $\mathrm{Gly}_{185}-\mathrm{Ser}_{186}-\mathrm{Gly}_{187}$ - while the other started Cys ${ }_{189}-\mathrm{Ile}_{190}$-Gln $\mathrm{Gl}_{191}$ - showing incomplete cleavage of the $\mathrm{Arg}_{188}-\mathrm{Cys}_{189}$ bond. Both sequences were followed through $\mathrm{Glu}_{204}$.

From a tryptic cleavage of FBP conducted in phosphate buffer followed by opening of the disulphide bonds and gel filtration a methionine containing peak was isolated which also consisted of two peptides. One of these, $\mathrm{Lys}_{42}-\mathrm{Asn}_{43}$ $\mathrm{Ala}_{44^{-}}$, was known and the other could therefore be followed 12 step starting Phe $_{64}-\mathrm{Asn}_{65}-\mathrm{Trp}_{66}$ -

The purified cyanogen bromide fragments (except the small N-terminal CNBr-I the sequence of which was already known) were used as starting material for the generation of peptides necessary to complete the sequence of FBP. In Table $I$ is shown the amino acid compositions of CNBr-II, CNBr-III and CNBr-IV as obtained from the sequence and from amino acid analyses. In all three cases a fair agreement between the two sets of data is obtained.

Digestion of $\mathrm{CNBr}$-III with clostripain and gel filtration gave rise to four peaks (not shown). One was sequenced 20 steps and shown to contain two peptides. These were identified as $\mathrm{Thr}_{128}-\mathrm{Ser}_{122^{-}}-\mathrm{Tyr}_{130^{-}}$and $\mathrm{Phe}_{158^{-}}$Asp $_{159^{-}}-\mathrm{Phe}_{160^{-}}$.
The first one was known while the last one in part was new.

CNBr-III was cleaved with S. aureus V8 protease and gel filtration on Biogel P30 resulted in six peaks as shown in Figure 2. Rechromatography of peak S III gave a clean peptide which was sequenced 39 steps starting at $\mathrm{Asp}_{125} \mathrm{Cys}_{126^{-}}$ $\mathrm{Arg}_{127}$. Peak S VI was sequenced without further purification 17 steps beginning at $\mathrm{Ile}_{172}-\operatorname{Trp}_{173^{-}}$ $\mathrm{Ser}_{174}$. Amino acid analyses showed the presence of homoserine and homoserine lactone identifying the peptide as the C-terminal part of CNBr-III.

The remaining peaks S I, S II, S III and S V were all mixtures of peptides without importance for the completion of the sequence. The following expected sequences were identified: $\mathrm{Glu}_{73}-\mathrm{Pro}_{74}-\mathrm{Ala}_{75^{-}}, \quad \mathrm{Cys}_{89}-\mathrm{Ser}_{90}-\mathrm{Pro}_{91^{-}}, \quad \mathrm{Val}_{100^{-}}$ $\mathrm{Asn}_{101}-\mathrm{Gln}_{102^{-}}, \mathrm{Asp}_{118^{-}} \mathrm{Cys}_{119^{-}} \mathrm{Gln}_{120^{-}}$.

Cleavage of CNBr-II with S. aureus V8 protease resulted in a series of peptides which were separated as shown in Figure 3. A peptide contained in peak S4 started $\mathrm{Ile}_{58}-\mathrm{Ser}_{59}-\mathrm{Tyr}_{60^{-}}$ and was followed through $\mathrm{Asp}_{67}$. It contained homoserine and homoserine lactone and thus represented the C-terminal part of $\mathrm{CNBr}$-II. It had the following amino acid composition: $\mathrm{Asp}_{2}, \mathrm{Ser}_{1}, \mathrm{HSer}_{1}, \mathrm{Gly}_{1}, \mathrm{Ile}_{1}, \mathrm{Leu}_{1}, \mathrm{Tyr}_{2}, \mathrm{Phe}_{\text {, }}$, 


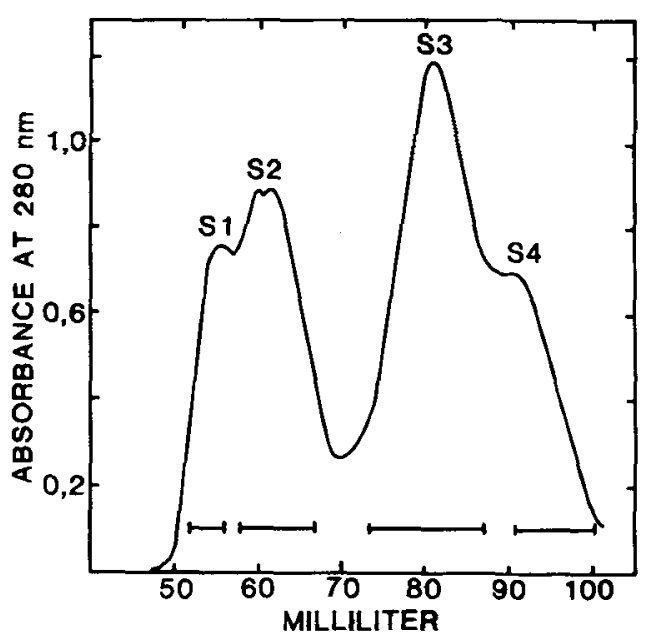

Figure 3. Gelfiltration of CNBr-II digested with S. aureus V8 protease on Biogel P30 $(0.9 \times 165 \mathrm{~cm})$ in 0.1 M-pyridine-acetate buffer $\mathrm{pH}$ 4. Flow-rate 8.5 $\mathrm{ml} \times \mathrm{hr}^{-1}$. Fractions: $1.3 \mathrm{ml}$.

His, 2-PECys, Lys $_{1}$ and Arg. The preceeding peak $S 3$ in Figure 3 contained two peptides: $\mathrm{Ala}_{54^{-}}$? - $\mathrm{Lys}_{56^{-}}$and $\mathrm{Asp}_{19}-\mathrm{Ala}_{20} \mathrm{Lys}_{21^{-}}$(N-terminal part of CNBr-II). Peaks S1 and S2 were not investigated further.

Cleavage of FBP, with intact disulfide bridges, by $\mathrm{S}$. aureus V8 protease upon gel filtration resulted in one peak containing high molecular weight material and one with the amino acid composition: Asp(1), Thr(2), Ser(2), Glu(2), $\operatorname{Pro}(2), \mathrm{Gly}(2)$ and Ile(1) which is compatible with the C-terminal 12 residues of FBP. Sequencing was possible for nine steps starting at $\mathrm{Glu}_{211}$-Asn ${ }_{212}$-Pro ${ }_{213}$. In this case $\mathrm{S}$. aureus protease acted in an unusual way since cleavage has taken place on the N-terminal side of a Glu.

Digestion of CNBr-IV with carboxypeptidase $\mathrm{Y}$ released four amino acids in the order shown in Figure 4. The C-terminal sequence of FBP is thus -Pro-Gin-Gly-Ile - $\mathrm{COOH}$.

Construction of the complete sequence (cf. Figure 5). In a previous publication (16) the N-terminal 62 residues were shown based on sequencing of reduced, vinylethylated FBP and one of the $\mathrm{CNBr}$ fragments, $\mathrm{CNBr}-\mathrm{II}$. This sequence has been confirmed and positions 52 and 58 identified as isoleucines. Position 53 was erroneously published as Gly while it in fact is
Glu. From CNBr-II digested with S. aureus V8 protease a peptide was isolated which began at Ile $_{58}$ and was sequenced through $\mathrm{Asp}_{67}$. Another peptide found as the main component in a mixture began at $\mathrm{Ala}_{54}$ and was sequenced through $\mathrm{Asp}_{67}$ confirming the sequence. Positions 49 and 55 were vacant in all cases.

The overlap between $\mathrm{CNBr}$-II and $\mathrm{CNBr}$-III was provided by a tryptic peptide isolated from a digest of FBP. It was sequenced 12 steps starting at $\mathrm{Phe}_{64}$ together with an already known sequence starting at $\mathrm{Lys}_{42}$. CNBr-III starting at $\mathrm{Glu}_{73}$ was previously sequenced 30 steps through $\mathrm{Gln}_{102}$ (16). This sequence was repeated and extended to include $\mathrm{Cys}_{1 \text { (q. }}$. Part of this sequence was confirmed $\left(\mathrm{Cys}_{89}-\right.$ Leu $\left._{144}\right)$ by sequencing a peptide obtained by cleavage of $\mathrm{CNBr}$-III with $\mathrm{S}$. aureus V8 protease.

The sequence of FBP was extended further by a tryptic peptide obtained by cleavage of FBP which began at $\mathrm{Val}_{109}$ and was followed through Gly $_{139}$. The last 15 residues of the sequence was confirmed and extended through Pro $_{163}$ by a peptide obtained from cleavage with $S$. aureus V8 protease. A six residues overlap was obtained by a clostripain derived peptide and the sequence extended through $\mathrm{Tyr}_{177}$. A prolongation to

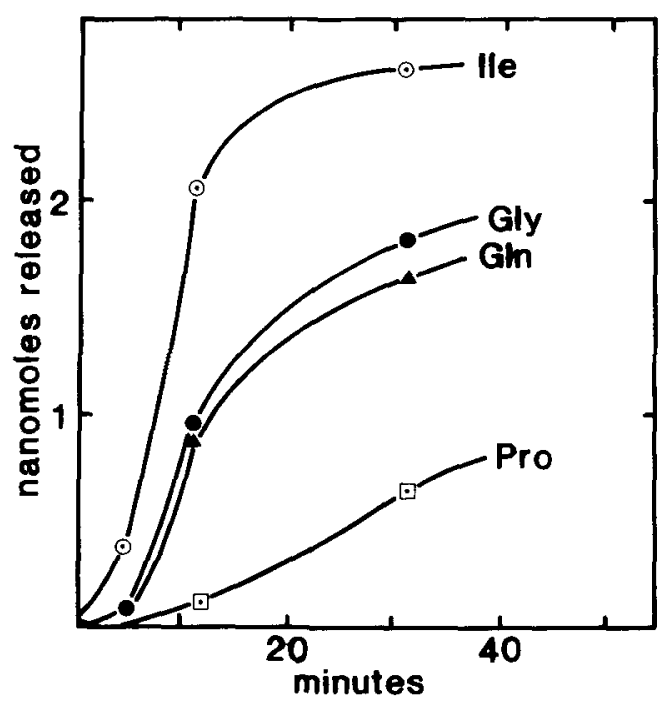

Figure 4. Digestion of CNBr-IV with carboxypeptidase $\mathrm{Y}$ in $0.2 \mathrm{M}$-ammoniumacetate, pH 5. 0. Enzyme-substrate ratio: $1: 200$. 
IB SVENDSEN et al.: Amino acid sequence of folate-binding protein

1 10 20

Ala-Gln-Ala-Pro-Arg-Thr-Pro-Arg-Ala-Arg-Thr-Asp-Leu-Leu-Asn-Val-Cys-Met-Asp-Ala-Lys-His-His-Lys-Ala-

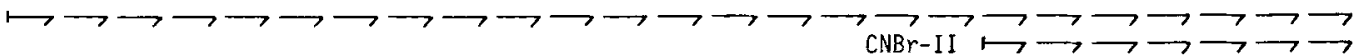

30

Glu-Pro-Gly-Pro-Glu-Asp-Ser-Leu-His-Glu-Gln-Cys-Ser-Pro-TrP
९ 50

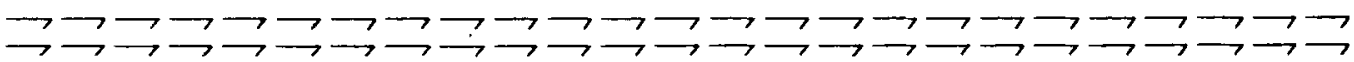

60

70

Ser-Ile-Glu-Ala- ? -Lys-Asp-Ile-Ser-Tyr-Leu-Tyr-Arg-Phe-Asn-Trp-Asp-His-Cys-Gly-Lys-Met-Glu-Pro-Ala-

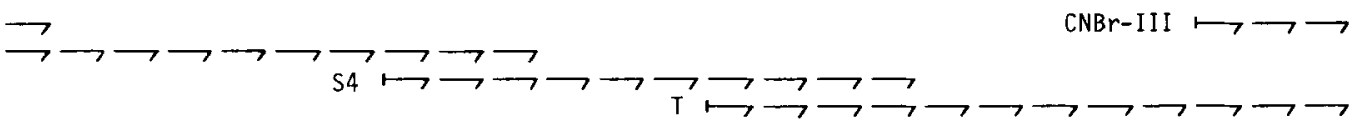
80

Cys-Lys-Arg-His-Phe-I le-GIn-Asp-Thr-Cys-Leu-Tyr-Glu-Cys-Ser-Pro-Asn-Leu-GIy-Pro-Trp-Ile-Arg-Glu-Val-

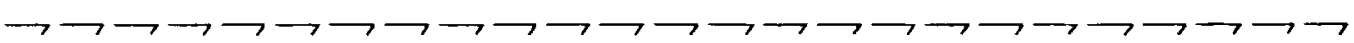

Asn-Gln-Arg-Trp-Arg-Lys-Glu-Arg-Val-Leu-Gly-Val-Pro-Leu-Cys-Lys-Glu-Asp-Cys-GIn-Ser-Trp-Trp-Glu-Asp$\longrightarrow \longrightarrow \longrightarrow \longrightarrow \longrightarrow \longrightarrow \longrightarrow \longrightarrow$

$$
\mathrm{T}-2 \longmapsto \longrightarrow \longrightarrow \longrightarrow \longrightarrow \longrightarrow \rightarrow \longrightarrow \rightarrow \longrightarrow
$$

130

1408

150

Cys-Arg-Thr-Ser-Tyr-Thr-Cys-Lys-Ser-Asn-Trp-His-Lys-Gly-Trp-Asn-Trp-Thr-Ser-Gly-Tyr-Asn-Gln-Cys-Pro-

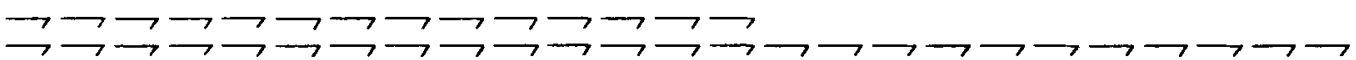

160

170

Val-Lys-Ala-Ala(His, Cys) Arg-Phe-Asp-Phe-Tyr-Phe-Pro-Thr-Pro-Ala-Ala-Leu-Cys-Asn-Glu-I le-Trp-Ser-His-

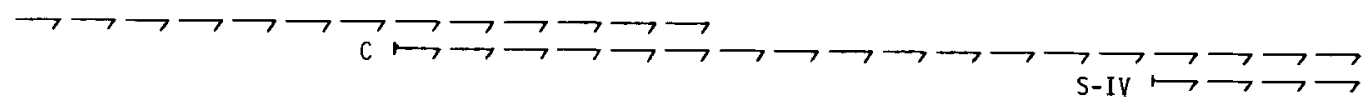

180

$\begin{array}{ccc}180 & 190 & 200 \\ \text { Ser-Tyr-Lys-Val-Ser-Asn-Tyr-Ser-Arg-Gly-Ser-Gly-Arg-Cys-Ile-Gln-Met-Trp-Phe-Asp-Pro-Phe-Gln-Gly-Asn- }\end{array}$

$\begin{array}{ccc}180 & 190 & 200 \\ \text { Ser-Tyr-Lys-Val-Ser-Asn-Tyr-Ser-Arg-Gly-Ser-Gly-Arg-Cys-Ile-Gln-Met-Trp-Phe-Asp-Pro-Phe-Gln-Gly-Asn- }\end{array}$

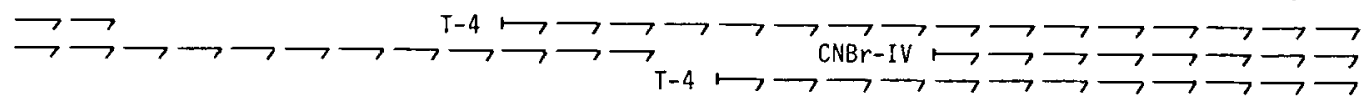

Pro-Asn-Glu-Glu-Val-Ala-Arg-Phe-Tyr-Ala-Glu-Asn-Pro-Thr-Ser-Gly-Ser-Thr-Pro-Gln-Gly-Ile COOH

Pro-Asn-Glu-Glu-Val-Ala-Arg-Phe-Tyr-Ala-Glu-Asn-Pro-Thr-Ser-Gly-Ser-Thr-Pro-Gln-Gly-Ile COOH

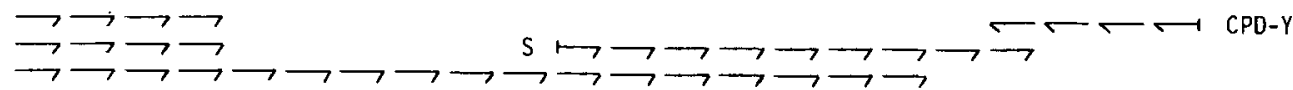

Figure 5. Complete amino acid sequence of folate binding protein from cow's milk. ---- denotes start and direction of sequencing. $\checkmark$ : carbohydrate attached. ? indicates undecided position. The different fragments used are identified by: $\mathrm{CNBr}=$ cyanogen bromide, $\mathrm{C}=$ clostripain, $\mathrm{T}=$ trypsin, $\mathrm{S}=\mathrm{S}$. aureus V8 protease, $\mathrm{CPD}-\mathrm{Y}$ = carboxypeptidase $\mathrm{Y}$. For further details see text. 
$\operatorname{Arg}_{188}$ was made by another S. aureus V8 protease derived peptide which started at $\mathrm{Ile}_{172}$.

The overlap between CNBr-III and CNBr-IV was obtained by two peptides both isolated from FBP after cleavage with clostripain. One sequence started at $\mathrm{Gly}_{185}$ and the other at Cys $\mathrm{S}_{189 .}$. Both were sequenced through $\mathrm{Glu}_{204}$.

The C-terminal CNBr-fragment has already been published (16) except for the final positions of the Pro and Gln in positions 219 and 220. A peptide purified from the digest of FBP by $S$. aureus V8 protease was sequenced nine steps and included Pro $_{219}$. Digestion of the same peptide with CPD-Y liberated four amino acids including $\mathrm{PrO}_{219}$. The Glu originally published based on amino acid compostion showed to be a Gln in the sequence.

\section{DISCUSSION}

Completion of the amino acid sequence of the folate binding protein from cow's milk showed this to be a single peptide chain consisting of 222 amino acid residues with carbohydrate attached at two or three side-chains. As discussed in the publication of the partial sequence the $\mathrm{N}$-terminal sequence was "ragged". Besides the sequence starting at $\mathrm{Ala}_{1}$ another was observed beginning at Ala. In some preparations used in the sequence work cleavage between $\mathrm{Arg}_{10}$ and $\mathrm{Thr}_{11}$ was seen (but never between $\mathrm{Arg}_{5}$ and $\mathrm{Thr}_{6}$ ). These findings point towards a trypsinlike activity in cow's milk (11).

The FBP is a glycoprotein as shown by the phenol-sulphuric acid method (6) and by the presence of glucosamine in amino acid hydrolysates. We found that carbohydrate was present in $\mathrm{CNBr}-\mathrm{II}$ as well as $\mathrm{CNBr}-\mathrm{III}$. CNBr-III has only one unassigned position (no. 141 in Figure 5) and the carbohydrate must therfore be located at this position. Position 143 is occupied by a Thr which suggests that the carbohydrate moiety is attached to an asparagine side-chain in position 141.

In CNBr-II two positions, 49 and 55, are vacant. Of these, position 49 is most likely occupied by a carbohydrate-linked asparagine since a Ser is located in position 51 . On the other hand, position 55 must have Ser or Thr if carbohydrate is attached. However, when the peptides obtained by cleavage of $\mathrm{CNBr}$-II with $\mathrm{S}$. aureus V8 protease were separated by gel filtration (see Figure 3) peak S3 which contained a peptide starting at $\mathrm{Ala}_{54}$ was negative with respect to carbohydrate while peaks S1 and S2 were strongly positive. It is possible therefore that position 55 is occupied by an amino acid which is modified in such a way that its PTH-derivative was not identified.

Positions 155 and 156 in the sequence have not been definitely assigned. A peptide obtained by digestion with pepsin, Asn ${ }_{147}-\mathrm{Phe}_{160}$, was treated with CPD-Y and the release of amino acids agrees with the sequence shown in Figure 5 but the similar yields of His and 2-PECys leave some doubt on their relative position.

Several attempts were made to determine the disulphide bond arrangement in FBP, but without success. Further studies with different approaches are needed to locate the eight disulphide bridges.

A comparison of the amino acid composition based on the sequence with that obtained from amino acid analysis is made in Table I. A reasonable good agreement is seen, the largest deviations found for Cys and Trp. The lack of two Asx residues in the composition derived from the sequence may be due to the two carbohydrate-linked Asn's in positions 49 and 141. The amino acid composition based on amino acid analysis used here deviates slightly from that originally published. A redetermination was made on FBP which had not been previously spray-dried.

The molecular weight of FBP calculated from the sequence is about 25.700 for the protein part. The uncertainty is introduced by the unassigned position 55 in the sequence.

The amino acid composition of FBP from cow's milk determined by SALTER et al. (14) is included in Table $I$. The values have been recalculated to a molecular weight of 25.700 for direct comparison. Also in this case a fair agreement with the sequence is seen.

Determination of the molecular weight by sedimentation equilibrium centrifugation gave $30.000+1-2000$ (16). Within these limits the carbohydrate content varies then between 8 and $20 \%$. The determination of carbohydrates in different batches of FBP has given values rang- 
ing from 3 to $10 \%$. SALTER et al. (14) have determined the content of the individual carbohydrates in FBP and showed that approximately $40 \%$ is contributed by $\mathrm{N}$-acetylglucosamine and $\mathrm{N}$-acetylgalactosamine. These authors found a carbohydrate content of $10 \%$. The phenol-sulphuric acid method used in our studies does not detect the presence of aminosugars and sialic acid. It is conceivable then that part of the deviation in molecular weight determination based on our centrifuge studies and sequence studies can be explained by the content of galactosamine and glucoamine.

SALTER et al, (14) determined the molecular weight to 35.000 from sedimentation equilibrium studies. We are unable to explain the large discrepancy between our and their values but a difference in experimental technique was that they used $6 \mathrm{M}$-guanidinium chloride as solvent.

Inspection of the amino acid sequence with respect to charge shows an interesting distribution of positive charges. These tend to cluster, the most striking example being $\mathrm{Lys}_{21}-\mathrm{His}_{22}$ His $_{23}-$ Lys $_{24}$, but also $\operatorname{Arg}_{41}-\mathrm{Lys}_{42}$, $\operatorname{Lys}_{77}-\mathrm{Arg}_{78^{-}}$ $\mathrm{His}_{79}, \quad \mathrm{Arg}_{103}-\mathrm{Trp}_{104}-\mathrm{Arg}_{105}-\mathrm{Lys}_{106}-\mathrm{Glu}_{107}-\mathrm{Arg}_{108}$ and $\mathrm{His}_{137} \mathrm{Lys}_{138}$ illustrate this. It will be interesting to learn if any of these charge-clusters are important for the strong binding of folate or its polyglutamyl derivative.

Prediction of the secondary structure by the CHOU and FASMAN method (5) shows a high (approx. $40 \%$ ) content of $\alpha$-helix while the $\beta$ structures only amounts to approx. $15 \%$.

Comparison of the amino acid sequence of FBP with those of other milk proteins such as $\alpha$-lactalbumin (4) and $\beta$-lactoglobulin (3) has not revealed any sequence homologies. Comparison with the sequence of tetrahydrofolate reductase from E. coli (1) and L. casei (1) also failed in showing homology. To our knowledge the amino acid sequence shown here represents a novel family of proteins the only other member hitherto sequenced in part is the one isolated from human milk (17).

\section{ACKNOWLEDGEMENTS}

We wish to thank professor MARTIN OTTESEN for critical review of the manuscript and mss BODIL CORNELIUSSEN and LONE SøRENSEN for expert technical assistance.

\section{REFERENCES}

1. Antony, A. C. . C. Utley, K. C. van Horne \& J. F. KOLHOUSE: Isolation and characterization of a folate receptor from human placenta. J. Biol. Chem. 256, 9684-9692 (1981)

2. Bennett, C. D.: Similarity in the sequence of $\mathrm{E}$. coli dihydrofolate reductase with other pyridine nucleotide-requiring enzymes. Nature 248, 67-68 (1974)

3. Braunitzer, G. , R. Chen, B. Schrank \& A. STANGL: Automatische sequenzanalyse eines protein ( $\beta$-lactoglobulin AB). Z. Physiol. Chem. 353 , 832-834 (1972)

4. Brew, K. , F. J. Castellino, T. C. Vanaman \& R. L. HILL: The complete amino acid sequence of bovine $\alpha$-lactalbumine. J. Biol. Chem. 245 , 4570-4582 (1970)

5. ChOU, P. Y. \& G. D. Fasman: Prediction of the secondary structure of proteins from their amino acid sequence. In. Adv. Enzym. vol 47 pp 45 (A. Meister, Ed. ) J. Wiley and Sons (1978)

6. Dubois, M. , K. A. Gilles, J. K. Hamilton, P. A REBERS \& F. SMITH: Colorimetric method for determination of sugars and related substances. Anal. Chem. 28, 350-356 (1956)

7. Fischer.C.D. . M. Da Costa \& S.P. RothenberG: Properties of purified folate-binding proteins from chronic myelogenous leukemia cells. Biochim. Biophys. Acta 543, 328-339 (1978)

7. Friedman. M. . L. H. Krull \& J. F. Cavins: The chromatographic determination of cystine and cystein residues in protein as $\mathrm{S}-\beta$-(4-pyridylethyl) cystein. J. Biol. Chem. 245, 3868-3871 (1970)

9. Henderson, G. B. , E. M. Zevely \& F. M. HuenNEKENS: Purification and properties of a membrane-associated folate-binding protein from Lactobacillus casei. J. Biol. Chem. 252, 3760-3765 (1977)

10. Johansen, J. T. , C. Overballe-Petersen, B. MARTIN, V. HASEMANN \& I. SVENDSEN: The complete amino acid sequence of copper, zink superoxide dismutase from Saccharomyces cereviciae. Carisberg Res. Commun. 44, 201-217 (1979)

11. Rollema, H. S. S. Visser \& J. K. Poll: On the determination, purification and characterization of the alkaline proteinase from bovine milk. Neth. Milk Dairy J. 35, 396-399 (1981)

12. Rubinoff, M. C. Schreiber \& S. WAXMaN: The isolation and characterization of the folate binding protein from goat milk. FEBS Letters 75, 244-248 (1977)

13. Salter, D. N. , J. E. Ford, K. J. Scott \& P. ANDREWS: Isolation of the folate-binding protein from cow's milk by the use of affinity chromatography. FEBS Letters 20, 302-306 (1972) 
14. Salter, D. N. , K. J. Scott, H. Slade \& P. ANDREW: The preparation and properties of folatebinding protein from cow's milk. Biochem. J. 193, 469-476 (1981)

15. SPECTOR, R.: Identification of folate binding macromolecule in rabbit choroid plexus. J. Biol. Chem. 252, 3364-3370 (1977)

16. Svendsen, I. , B. Martin, T. G. Pedersen, S. I HANSEN, J. HOLM \& J. LYNGBYE: Isolation and characterization of the folate binding protein from cow's milk. Carlsberg Res. Commun. 44, 89-99 (1979)

17. SVEndSen, I. S I. HANSEN, J. Holm \& J. LyngBye: Amino acid sequence homology between human and bovine low molecular weight folate binding protein isolated from milk. Carlsberg Res. Commun. 47, 371-376 (1982)

18. Suleiman, S. A. \& R. SPector: Purification and characterization of a folate binding protein from porcine choroid plexus. Arch. Biochem. Biophys. 208, 87-94 (1981)

19. Suzuki, N. \& C. WAGNer: Purification and characterization of a folate binding protein from rat liver cytosol. Arch. Biochem. Biophys. 199, 236248 (1980)

20. WaXmann, S. \& C. SCHREIBER: The purification and characterization of the low molecular weight human folate binding protein using affinity chromatography. Biochemistry 14, 5422-5428 (1975) 